\title{
Rancang Bangun Pengukur Suhu Tubuh Berbasis Arduino Sebagai Alat Deteksi Awal Covid-19
}

\author{
Rindi Wulandari \\ Program Studi Teknik Elektro, Fakultas Teknik, Universitas Swadaya Gunung Jati \\ Jl. Pemuda No.32 45132 Cirebon \\ Email : wulandarindi@gmail.com
}

\begin{abstract}
Maintaining health is very important for life especially in the current Covid-19 pandemic. One of the protocols imposed by the government for people who do in public spaces or open facilities is to check body temperature. In this study, arduino-based body temperature gauges were designed to have reminder alarms if the body temperature was above 37.30 and connected to a computer device via bluetooth. This body temperature gauge utilizes the DS18B20 sensor to measure temperature in celsius $(0 C)$. Body temperature data is also displayed on the $16 \times 2(\mathrm{~cm}) L C D$ found on the appliance. The test results of body temperature measuring instruments compared to thermo guns and have a deviation range of $1.16 \%-2.02 \%$. This body temperature gange is expected to be installed in public places that need to conduct checks on the people who will be active in the room, the operator can stand at the control table so that it does not come into direct contact with the community.
\end{abstract}

Keywords: body temperature gauge, arduino, DS18B20 sensor

\begin{abstract}
Abstrak: Menjaga kesehatan merupakan hal yang sangat penting bagi kehidupan terutama di masa pandemi Covid- 19 sekarang. Salah satu protokol yang diberlakukan oleh pemerintah bagi masyarakat yang berkegiatan di ruang umum atau fasilitas terbuka adalah memeriksa suhu tubuh. Dalam penelitian ini dibuat rancang bangun alat pengukur suhu tubuh berbasis arduino yang memiliki alarm penging at jika suhu tubuh berada diatas angka 37.30 dan terhubung ke perangkat komputer melalui bluetooth. Alat pengukur suhu tubuh ini memanfaatkan sensor DS18B20 untuk mengukur suhu dalam satuan celcius (0C). Data suhu tubuh juga ditampilkan pada LCD 16×2 (cm) yang terdapat pada alat. Hasil pengujian alat ukur suhu tubuh dibandingkan dengan thermo gun dan memiliki rentang penyimpangan $1.16 \%$ $2.02 \%$. Alat pengukur suhu tubuh ini diharapkan dapat dipasang di tempat-tempat umum yang membutuhkan untuk melakukan pemeriksaan terhadap masyarakat yanga akan beraktifitas diruangan tersebut, operator dapat berdiri di meja kendali sehingga tidak kontak langsung dengan masyarakat.
\end{abstract}

Kata kunci: pengukur suhu tubuh, arduino, sensor DS18B20

\section{PENDAHULUAN}

Pendahuluan menguraikan latar belakang permasalahan yang diselesaikan, isu-isu yang terkait dengan masalah yg diselesaikan, ulasan penelitan yang pernah dilakukan sebelumnya oleh peneliti lain yg relevan dengan penelitian yang dilakukan.

Menjaga kesehatan merupakan hal yang penting dan sangat berharga bagi kehidupan manusia. Apabila kesehatan terganggu, maka akan berpengaruh terhadap aktivitas sehari-hari (Eddy R, 2016). Kesehatan perlu diperhatikan bagi semua orang terutama saat musim pandemi Covid-19 sekarng.

Pemerintah menerapkan aturan Adaptasi Kebiasaan Baru (AKB) untuk masyarakat guna melakukan pencegahan dini penularan Covid-19. Termasuk diantaranya dalam berperilaku sehari-hari harus mematuhi protokol jaga jarak dan hidup bersih. Beberapa alat kesehatan mengalami lonjakan permintaan sehingga terjadi kekosongan dipasaran. Seperti, masker, handsanitizer, thermometer tembak, dan sarung tangan. 
Saat pandemi Covid-19, pengukuran suhu tubuh manusia menjadi suatu hal yang penting sebagai tindakan untuk mendeteksi gejala awal Covid-19, selain itu sebagai suatu usaha untuk mengurangi kontak langsung dan menerapkan protokol jaga jarak, dilakukan studi mengenai pengukuran temperatur yang jika ditemukan suatu hal yang abnormal maka alat pengukur akan otomatis mengeluarkan suara alarm yang berarti sebuah informasi untuk waspada dan sebagai peringatan dini (Goda V, SK. A, 2020).

Oleh karena itu, pada studi kali ini bertujuan untuk membuat alat pengukur suhu tubuh otomatis berbasis arduino yang fungsinya seperti thermometer tembak, disertai alarm peringatan saat tedeteksi hasil yang abnormal dan petugas yang mengecek dapat memantau dari jarak jauh sekitar 5 meter dari lokasi pengukuran agar tetap mematuhi protokol, dan data pengukuran diakses petugas melalui bluetooth pada smartphone atau laptop.

\section{METODE PENELITIAN}

Penelitian yang dilakukan termasuk penelitian terapan, dengan metode penelitian eksperimental (Kothari, 2009). Tahapan penelitian yang dilakukan adalah studi literatur, perancangan perangkat lunak, perancangan perangkat keras, pengujian sistem, dan analisis ditunjukan pada Gambar 1.

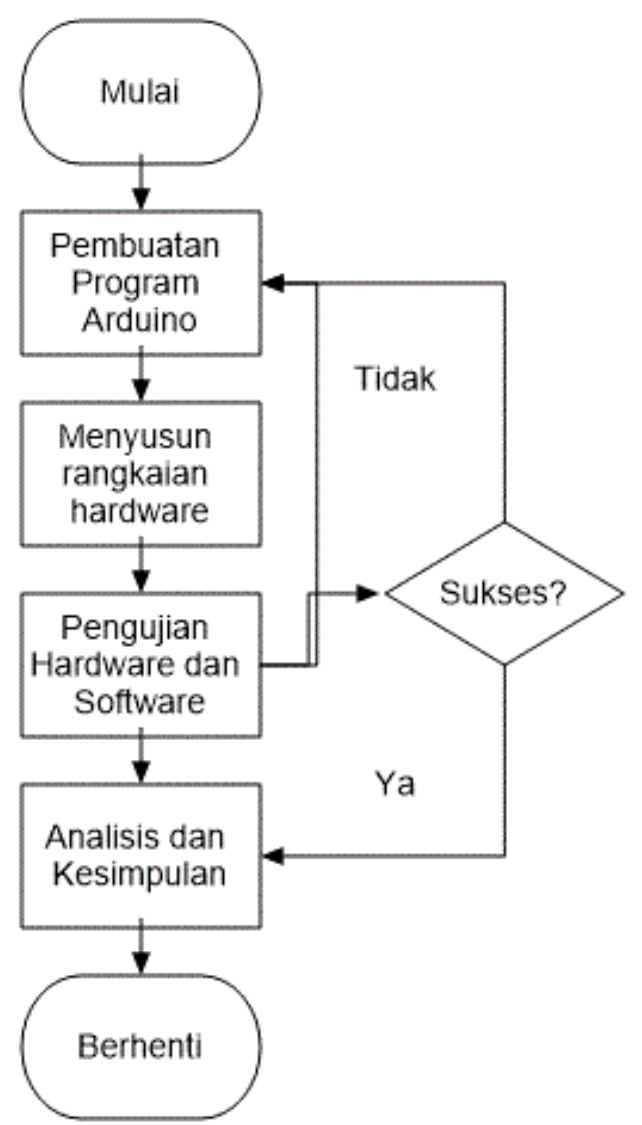

Gambar 1. Tahapan Penelitian

\subsection{Studi Literatur}

Pada tahap ini dilakukan pencarian referensi yang sesuai dengan penelitian terkait khususnya yang membahas suhu tubuh. Pengumpulan referensi sangat penting dilakukan dalam rangka melengkapi atau mendukung penelitian, seperti pengukuran suhu tubuh manusia, dasardasar arduino dan sensor DS18B20. 


\subsection{Perancangan Perangkat Lunak}

Perancangan ini menggunakan program aplikasi Integrated Developtment Enviroenment (IDE) yang digunakan pada modul arduino dengan bahasa pemograman C. Aplikasi program IDE ini digunakan untuk menampilkan data sensor. Hasil data program yang dibuat dalam teks editor (sketch) disimpan dalam file dengan ekstensi .ino.

\subsection{Perancangan Perangkat Keras}

Pada tahap ini dilakukan rancangan berupa layout berdasarkan komponen pendukung dari sistem yang akan dibangun. Perancangan ini terdiri dari sensor suhu, modul arduino, bluetooth, dan LCD. Proses perancangan alat pengukur suhu tubuh dapat dilihat pada Gambar 2.

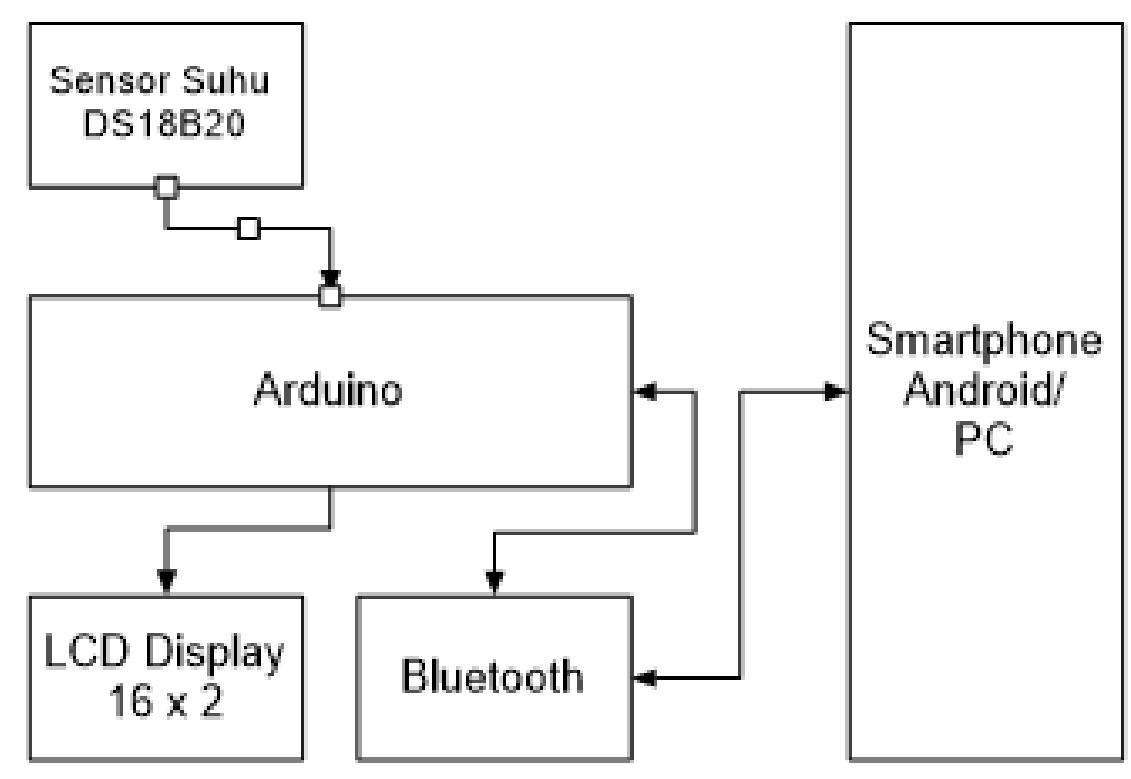

Gambar 2. Blok Diagram Alat Ukur Suhu Tubuh

Alat ukur detak jantung dan suhu tubuh terdiri dari beberapa bagian seperti dibawah ini :

1. Power supply berfungsi sebagai catu daya ke semua bagian kecuali smartphone android/ PC

2. Arduino sebagai pengendali sensor, bluetooth dan keluaran data.

3. LCD 2x16 berfungsi untuk menampilkan data suhu dan detak jantung.

4. DS18B20 merupakan sensor untuk mendeteksi suhu.

5. Bluetooth digunakan sebagai perantara pengiriman dan penerimaan data.

6. Smartphone android/PC sebagai penampil data suhu dan detak jantung. 


\subsection{Rancangan Sensor Suhu DS18B20}

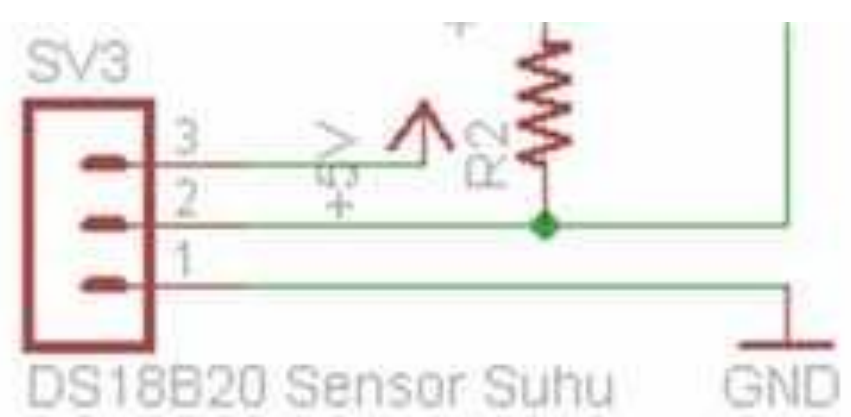

Gambar 3. Rangkaian Sensor Suhu DS18B20 (Manurung Briston, 2019)

Temperature sensor DS18B20 memiliki tegangan kerja 5 Volt, beroperasi pada suhu $-55^{\circ}$ celcius hingga $+125^{\circ}$ celcius. Keunggulan DS18B20 yaitu output berupa data digital dengan nilai ketelitian $0.5^{\circ}$ celcius selama kisaran temperature $10^{\circ}$ celcius sampai $+85^{\circ}$ celcius.Jadi sensor suhu DS1820 mengirimkan data digital berupa sinyal pulsa yang mengindikasikan suatu suhu tertentu, kemudian output sensor diterimaoleh mikrokontroler Arduino sehingga mempermudah pembacaan. Pada Gambar 3, menunjukkan output dari DS18B20 dapat langsung di koneksikan ke ADC internal Mikrokontroler Arduino.

\section{HASIL DAN DISKUSI}

Berdasarkan hasil perancangan perangkat lunak dan perangkat keras sistem monitoring suhu tubuh, maka diperoleh hasil sebagai berikut:

\subsection{Pengujian Sensor Suhu Tubuh}

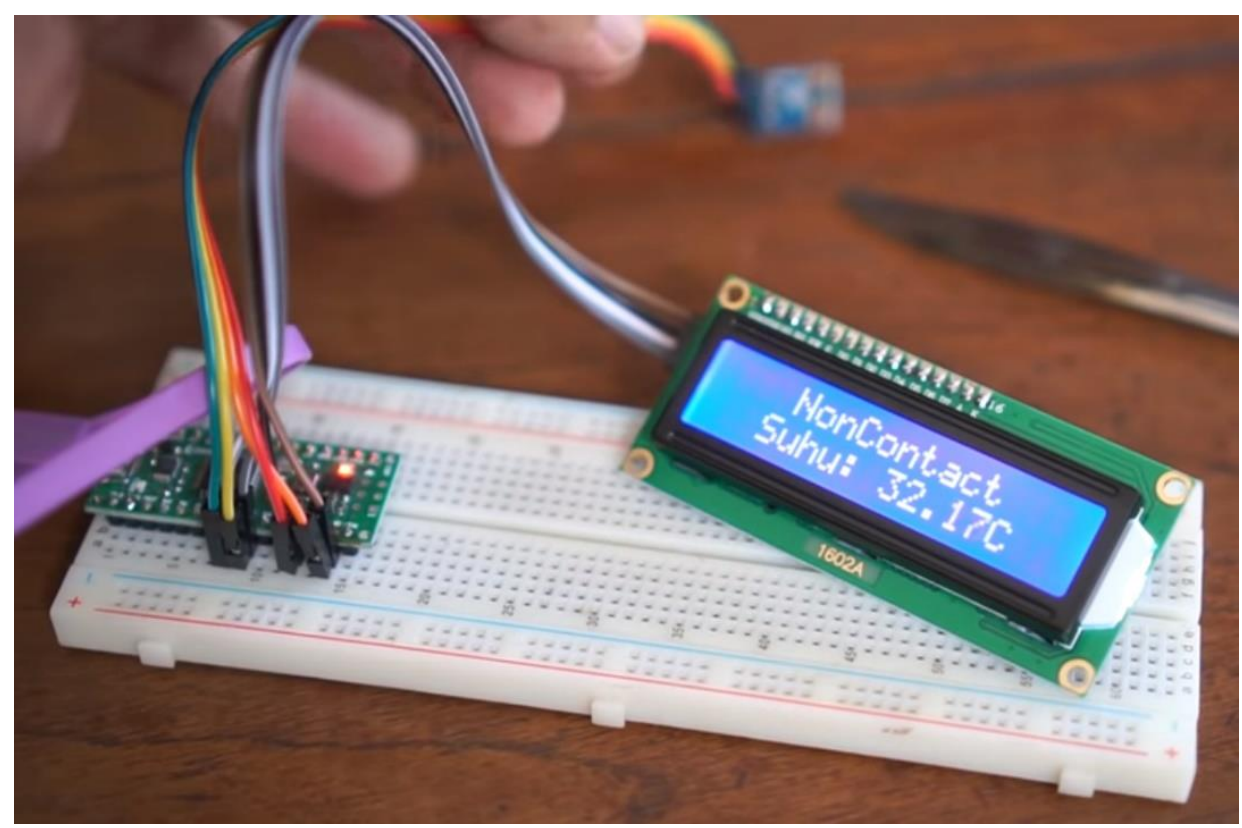

Gambar 4. Hasil Pengukuran suhu tubuh dengan sensor DS18B20

Pada Gambar 4, menunjukkan hasil pengukuran suhu tubuh dengan sensor DS18B20. Cara mengukur suhu tubuh yaitu dengan meletakkan sensor DS18B20 pada dahi maupun ketiak. 
Kemudian, tunggu sekitar satu menit untuk melihat hasilnya. Untuk mengetahui hasil pengukuran dengan sensor DS18B20 dapat dilihat pada Tabel 1.

Tabel 1. Hasil Pengukuran Suhu Tubuh oleh Sensor DS18B20

\begin{tabular}{ccccc}
\hline Orang ke- & $\begin{array}{c}\text { Pengukuran 1 } \\
\left({ }^{\mathbf{}} \mathbf{C}\right)\end{array}$ & $\begin{array}{c}\text { Pengukuran 2 } \\
\left({ }^{\mathbf{0}} \mathbf{C}\right)\end{array}$ & $\begin{array}{c}\text { Pengukuran 3 } \\
\left({ }^{\mathbf{}} \mathbf{C}\right)\end{array}$ & $\begin{array}{c}\text { Rata-rata } \\
\left({ }^{\mathbf{O}} \mathbf{C}\right)\end{array}$ \\
1 & 36.50 & 36.70 & 36.30 & 36.50 \\
2 & 37.30 & 37.30 & 37.50 & 37.36 \\
3 & 36.80 & 36.60 & 36.80 & 36.73 \\
\hline
\end{tabular}

Orang pertama dan kedua adalah orang dalam kondisi sehat, sedangkan orang kedua dalam kondisi demam. Saat pengukuran suhu tubuh pada orang ke-dua, alarm secara otomatis berbunyi sebagai tanda peringatan.

\subsection{Pengujian Jarak Jangkauan Bluetooth}

Pengujian pada PC/Laptop ditekankan pada pengujian jarak. Pengujian ini dilakukan untuk mengetahui jarak maksimal antara alat ukur dengan PC/Laptop. Pengukuran dilakukan pada jarak $5 \mathrm{~m}, 10 \mathrm{~m}, 15 \mathrm{~m}$, dan $20 \mathrm{~m}$ dengan 2 kondisi yaitu ditempat yang ada jaringan wifi dan jauh dari jangkauan wifi. Tabel 2 merupakan hasil dari pengujian jarak pada $P C /$ Laptop dengan alat ukur.

Tabel 2. Pengujian Jarak jangkauan Bluetooth

\begin{tabular}{ccc}
\hline Jarak $(\mathbf{m})$ & Hasil & Keterangan \\
\hline 5 & Bisa & Lancar \\
\hline 10 & Bisa & Lancar \\
\hline 15 & Bisa & Tertunda 1-3 detik \\
\hline 20 & Tidak bisa & Tidak terhubung \\
\hline
\end{tabular}

Jarak jangkauan optimal bluetooth HC-05 yang disarankan adalah $10 \mathrm{~m}$. Jaringan wifi tidak mempengaruhi koneksi bluetooth HC-05 dengan smartphone android karena alat ini tidak tergantung pada data internet maupun jaringan internet.

\subsubsection{Pengujian Presisi Alat}

Pengujian presisi alat ini dilakukan dengan membandingkan hasil pengukuran rata-rata dari sensor DS18B20 dengan alat pengukur suhu tubuh yang ada dipasaran. Dalam pengukuran oleh alat yang ada dipasaran juga dilakukan 3 kali pengukuran terhadap masing- masing orang yang diukur suhu tubuhnya. Selanjutnya, dilakukan perhitungan eror dengan rumus galat eror yang dihitung dengan persamaan (1).

$$
\% \text { eror }=\frac{\mid \text { pengukuran sensor }- \text { pengukuran termometer dipasaran } \mid}{\text { engukuran termometer dipasaran }} \times 100
$$

Pada tabel 3 merupakan hasil data dari masing-masing hasil pengukuran dan persentase eror dari alat terhadap termometer digital yang ada dipasaran. 
Tabel 2. Pengujian Jarak jangkauan Bluetooth

\begin{tabular}{|c|c|c|c|c|}
\hline $\begin{array}{c}\text { Orang } \\
\text { ke- }\end{array}$ & $\begin{array}{c}\text { Hasil pengukuran } \\
\text { sensor DS18B20 } \\
\left({ }^{\circ} \mathrm{C}\right) \\
(\mathrm{X})\end{array}$ & $\begin{array}{c}\text { Hasil pengukuran } \\
\text { Termometer digital } \\
\left({ }^{\circ} \mathrm{C}\right) \\
(\mathrm{Y})\end{array}$ & $\begin{array}{l}\text { Selisih } \\
\left({ }^{\circ} \mathbf{C}\right) \\
(\mathrm{X}-\mathrm{Y})\end{array}$ & $\begin{array}{c}\text { Persentase } \\
\text { penyimpangan } \\
(\%)\end{array}$ \\
\hline 1 & 36.50 & 37.10 & 0.60 & 1.61 \\
\hline 2 & 37.36 & 37.80 & 0.44 & 1.16 \\
\hline 3 & 36.73 & 36.00 & 0.73 & 2.02 \\
\hline
\end{tabular}

Hasil pengujian presisi alat ukur suhu tubuh mempunyai selisih rata- rata 1.16-2.02\%

\subsection{Analisis}

Berdasarkan hasil pengujian yang telah dilakukan, rancangan alat dan aplikasi android dapat berjalan dengan baik. Aplikasi android dan alat ukur penulis terdapat kelebihan antara lain:

a. Dapat menampilkan suhu tubuh secara real time pada alat dan laptop/PC

b. Tampilan aplikasi sederhana dan mudah digunakan.

c. Penggunaan alat sangat mudah.

\section{PENUTUP}

\subsection{Kesimpulan}

Pada penelitian ini telah dibuat rancang bangun alat ukur suhu tubuh manusia berbasis arduino dengan menggunakan sensor DS18B20 dan bluetooth HC-05 untuk mentransfer data pada android/ PC/ Laptop. Dilakukan juga uji fungsi serta pengujian presisi alat. Hasil uji presisi alat dengan termometer yang ada dipasaran memiliki hasil galat eror sebesar 1.16-2.02\%. Jarak jangkauan optimal bluetooth HC-05 yang ada pada alat adalah $10 \mathrm{~m}$.

\subsection{Saran}

Pada penelitian berikutnya disarankan melakukan uji kestabilan pada alat, memperbaiki package dari alat agar lebih terlihat simpel dan membuat tampilan alat menarik juga membuat data base dari hasil pengukuran suhu.

\section{DAFTAR PUSTAKA}

Ardianto Pranata., Jaka Prayudha., Teja Sandika. (2017). Rancang Bangun Alat Pendeteksi Dehidrasi Dengan Metode Fuzzy Logic Berbasis Arduino. Jurnal SAINTIKOM Vol. 16, No. 3,September 2017 ISSN: 1978-6603

Briston Manurung. (2019). Rancang Bangun Pendeteksi Denyut Jantung dan Suhu Tubuh Portabel Berbasis Mikrokontroller Arduino Uno. Medan. Program Studi D-3 Fisika, Fakultas Matematika dan Ilmu Pengetahuan Alam, Universitas Sumatera Utara. http://repositori.usu.ac.id/handle/123456789/22599

Eddy Friyanto. (2016). Perancangan Pengukur Detak Jantung Dan Suhu Tubuh Berbasis Arduino Serta Smartphone Android. Surakarta. Skripsi Program Studi Teknik Elektro, Fakultas Teknik, Universitas Muhammadiyah Surakarta

Gamal Centaury., Engelin Shintadewi. (2018). Prototipe Pengukur Tinggi, Berat, Dan Suhu Badan Berbasis Arduino Uno Dan Labview. JETri, Vol. 16, No. 1, Agustus 2018, Hlm. 55 - 70, P-ISSN 1412-0372, E-ISSN 2541-089X 
Goda Vasantharao., SK Arifunneesa. (2020). Temperature Detection and Automatic Sanitization and Disinfection Tunnel-COVID 19. The International journal of analytical and experimental modal analysis Volume XII, Issue VI, June/2020 ISSN NO:0886-936 Page No: 1175-1181.

H. Muhammad Asraf., K.A. Nur Dalila., A.W. Muhammad Hakim., R.H. Muhammad Faizzuan Hon. Development of Experimental Simulator via Arduino-based PID Temperature Control System using LabVIEW. Journal of Telecommunication, Electronic and Computer Engineering e-ISSN: 2289-8131 Vol. 9 No. 1-5

Navreetinder Kaur., Rita Mahajan., Deepak Bagai. (2016). Air Quality Monitoring System Based On Arduino Microcontroller. International Journal of Innovative Research in Science, Engineering and Technology (An ISO 3297: 2007 Certified Organization) Vol. 5, Issue 6, June 2016

Tan Suryani S., Alamsyah., Muhammad bachtiar., Ardi Amir., Benyamin B. (2018). Sistem Monitoring Detak Jantung dan Suhu Tubuh Menggunakan Arduino. Techno.COM, Vol. 17, No. 3, Agustus 2018: 323-332

W Widhiada., I N G Antara., I N Budiarsa., I M G Karohika. (2018). The Robust PID Control System of Temperature Stability and Humidity on Infant Incubator Based on Arduino AT Mega 2560. International Conference on SMART CITY Innovation 2018. IOP Conf. Series: Earth and Environmental Science 248 (2019) 012046 IOP Publishing doi:10.1088/1755-1315/248/1/012046

Yofi A., Rahman Arifuddin., Yusuf N. (2019). Rancang Bangun Alat Pendeteksi Detak Jantung, Suhu Tubuh, dan Tensimeter Berbasis Arduino Uno serta Smartphone Android. Seminar Nasional Fortei7-1 (Forum Pendidikan Tinggi Teknik Elektro Indonesia Regional VII), ISSN (online): 2621-5551 